\section{DNA Microarray Analysis of Hypothermic Murine Myocardium to Study Pathophysiology and Identify Forensic Biomarkers}

Keywords: Heart; Myocardium; Hypothermia; Transcriptome; DNA microarray; Quantitative PCR

\begin{abstract}
We used DNA microarray technology to analyze the myocardia transcriptome of mice killed via experimentally induced hypothermia. This analysis identified significant differential regulation of 3438 genes; specifically, 1704 genes were upregulated, and 1734 were downregulated in response to hypothermia. The gene encoding granzyme A was the most upregulated gene, and that encoding solute carrier family 41 member 3 was the most downregulated. Geneset analysis identified significant hypothermia-induced variation in 79 pathways, and we suggest that pathways related to granzyme $A$ and cell death may be involved in cardiac pathogenesis of hypothermia. Gene-function-category analysis demonstrated the most highly represented categories among the upregulated and downregulated genes were cellular process (biological process), binding (molecular function), and cell and cell part (cellular component). The presented findings clearly demonstrated that acute myocardial responses to hypothermia did occur; they also indicated several cardiac-related candidate genes as forensic biomarkers of hypothermia. Hypothermiainduced myocardial cell death would be an irreversible change that, we believe, may explain the circulatory failure, resistance to treatment, and high mortality associated with hypothermia. Furthermore, the present microarray data may facilitate development of immunohistochemical analysis and protocols to be used for human forensics and may be beneficial in clinical research on hypothermia.
\end{abstract}

\section{Introduction}

Hypothermia is classically defined as a core body temperature of less than $35{ }^{\circ} \mathrm{C}$. Hypothermia develops when adaptive thermoregulatory mechanisms are overwhelmed and hypothermia is a common danger even indoors and in temperate climates $[1,2]$. Macroscopically, hypothermia may cause the following: frostbite; bright-pink lividity [3]; hemorrhages in muscles [4]; cerebral edema [3]; venous thrombosis [2]; pulmonary edema [2,3,5]; bronchopneumonia [6]; hemorrhages in the stomach, ileum, and colon [3,5,6]; and diuresis [5]. Additionally, histological examinations reveal fatty changes in the liver and kidneys [7-9], vacuolization of liver cells [3] and pancreatic adenoid cells [10], renal tubular necrosis $[5,6]$, heat shock protein 70 accumulation in renal tubular epithelium and glomerular podocytes [11], and hemorrhagic pancreatitis $[3,5,6,8]$. Forensic differential diagnosis of hypothermia is often difficult because many of these autopsy findings are not specific to hypothermia. Therefore, diagnosis of hypothermia must be based partly on exclusion criteria and historical information. However, molecular biological methods may provide more definitive criteria for forensic diagnosis of hypothermia [12].

Hypothermia carries a high mortality rate due to circulatory

\section{Journal of}

Forensic Investigation

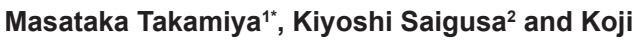 \\ Dewa $^{1}$ \\ ${ }^{\prime}$ Department of Forensic Medicine, Iwate Medical University, Iwate, \\ Japan \\ ${ }^{2}$ Department of Biology, Iwate Medical University, Iwate, Japan
}

\section{*Address for Correspondence}

Masataka Takamiya MD, PhD, Department of Forensic Medicine, Iwate Medical University, 2-1-1 Nishitokuta, Yahaba, Iwate 0283694, Japan, Tel: +81-19-698-1820; Fax: +81-19-908-8005; E-mail: mtakamiy@iwate-med.ac.jp

Submission: 20 January, 2016

Accepted: 16 March, 2016

Published: 21 March, 2016

Copyright: () 2016 Takamiya M, et al. This is an open access article distributed under the Creative Commons Attribution License, which permits unrestricted use, distribution, and reproduction in any medium, provided the original work is properly cited.

Reviewed \& Approved by: Dr. Robert Allen, Oklahoma State University, Center for Health Sciences, USA

failure [13]. Cardiac output and sinus rate decrease and arrhythmias (from atrial fibrillation to ventricular fibrillation) occur during hypothermia $[14,15]$. Therefore, it is important to document the cardiovascular state during hypothermia; consequently, we considered it worthwhile to assess hypothermia-induced changes to the myocardial transcriptome. In this study, the myocardial transcriptome in hypothermic mice was analyzed to examine the cardiac pathophysiology of mammalian hypothermia and to identify candidates for forensic biomarkers of human hypothermia. This study was designed both for the study of cardiac pathophysiology and to improve forensic practices; moreover, the findings should be beneficial for clinical research on hypothermia.

\section{Materials and Methods}

\section{Tissue samples}

A water-bath method described previously was adapted to induce hypothermia in mice [16]. Male ddY mice 7 weeks of age and weighing $36.3 \pm 6.8$ g were housed under controlled lighting (lights on at 7:00 am and off at 7:00 pm) and given free access to food and water. This was a preliminary study, and only male mice were used; therefore, potential differences due to sex should be addressed in future studies. Each mouse was anesthetized by sevoflurane inhalation and then confined in a metallic restraint cage that was kept in a water bath set at $10^{\circ} \mathrm{C}$ such that each mouse was immersed up to the neck in the cold water. Each animal died from continuous exposure to cold water for $42.8 \pm 12.6$ minutes. Immediately after death, a $2-\mathrm{mm}$ thick specimen from the anterior wall of the left ventricle was resected $3 \mathrm{~mm}$ from the heart apex for each animal. In all, 28 mice were subjected to hypothermia-induced death; four were used for DNA microarray analyses, four for selection of genes to be used as the internal standard, 10 for quantitative PCR analyses, and 10 for immunohistochemical 
Citation: Takamiya M, Saigusa K, Dewa K. DNA Microarray Analysis of Hypothermic Murine Myocardium to Study Pathophysiology and Identify Forensic Biomarkers. J Forensic Investigation. 2016; 4(1): 11.

analyses. Control mice $(\mathrm{n}=28)$ were sacrificed by inhalation of $\mathrm{CO}_{2}$, and the same part of each control left ventricle was examined ( $\mathrm{n}=4$ for DNA microarray, $\mathrm{n}=4$ for internal standard gene selection, $\mathrm{n}=$ 10 for quantitative PCR, $\mathrm{n}=10$ for immunohistochemistry). Because this was a forensic pathologic study, samples from hypothermic and separately control mice were collected from cadavers. In other words, death was the most important commonality between the hypothermic and control mice. Furthermore, the interval between initial $\mathrm{CO}_{2}$ exposure and death was extremely short in the control group, and this short time period may have precluded substantial changes in gene expression; therefore, $\mathrm{CO}_{2}$ exposure was an appropriate negativecontrol treatment for our purposes. For DNA microarray analyses, internal standard gene selection, and quantitative PCR analyses, each isolated tissue specimen was immediately soaked in $1.5 \mathrm{ml}$ RNAlater solution (Applied Biosystems, Carlsbad, CA), and stored at $-80{ }^{\circ} \mathrm{C}$ for 2 weeks. The research described in this report was conducted in accordance with the guidelines for animal experimentation from Iwate Medical University.

\section{DNA microarray methods}

RNeasy Fibrous Tissue Mini Kits (Qiagen, Valencia, CA) were used to extract total RNA samples from tissue specimens. All microarray procedures described here were performed at Tohoku Chemical Research Institute of Bio-system Informatics (Morioka, Japan). Electrophoresis through a $1 \%$ agarose gel, an absorptiometer, and a 2100 bioanalyzer (Agilent Technologies, Santa Clara, CA) were used to confirm the quality of the RNA samples; quality control criteria were as follows: OD260/280 > 1.5, OD260/230 > 1.0, no degradation in electrophoresis, $28 \mathrm{~S} / 18 \mathrm{~S}$ ribosomal RNA bands $>1.8$, RNA Integrity Number $>7$. The Mouse GE 4x44K v2 Microarray Kit (4 arrays, Agilent Technologies, Santa Clara, CA) was used according to the manufacturer's instructions to determine gene expression profiles. The analysis was performed with the two-color method; control samples were labeled with $\mathrm{Cy} 3$, and hypothermic samples were labeled with Cy5. Scanning of microarray slides was performed with Agilent Technologies Scanner G2505C and Agilent Feature Extraction 10.7.3.1 (Agilent Technologies, Santa Clara, CA). For further analysis, GeneSpring (Agilent Technologies, Santa Clara, CA) was also used. In addition, annotations of genes were based on the Gene and GenBank of National Center for Biotechnology Information (NCBI, Bethesda, MD). Thus, those probes that are not cataloged in Gene or GenBank were not annotated in the present study. This experiment was verified according to the minimum information about microarray experiment (MIAME) guidelines (Supplement 1) [17].

Quality control: Quality control for each feature (spot) was performed using the settings recommended by Agilent Technologies. Background signal was subtracted, and signal intensity of each feature was globally normalized via locally weighted scatter-plot smoothing (LOWESS). The following flag parameters were used: "Feature is saturated"; "Feature is not uniform"; "Feature is not positive and significant"; "Feature is not above background"; "Feature is a population outlier". For each of these parameters, one of the following terms was applied to each feature:

Detected: The data are reliable.
Not detected: The quality of data are undetermined.

Compromised: The data are unreliable.

Each gene was represented by four spots, and one of the following terms was applied to each spot:

Detected: All the parameters are "Detected".

Not detected: The parameters are combinations of "Detected" and "Not detected".

Compromised: One of the parameters is "Compromised".

For subsequent analyses, we used only genes for which all four spots were categorized as "Detected".

Selection of significantly regulated genes: The one-sample Student's t-test was performed to identify genes that exhibited significant differential expression in response to hypothermia. $\mathrm{P}$ values of 0.05 or lower were considered statistically significant. After the correction for multiple tests (Benjamini-Hochberg method), only five genes showed significant differences between the experimental and control samples. This phenomenon was due to the dispersion of gene expression data among four arrays. Therefore, these statistical methods were not used.

\section{Gene-set analysis:}

KEGG analysis: We used the KEGG (Kyoto Encyclopedia of Genes and Genomes) pathway database and previously published methods to perform gene-set analysis [18]. The mean of fold-changes among all quality-controlled genes were compared to the fold-change of each gene set. Z scores of fold-changes were calculated, and datasets with normal distributions were subject to statistical analysis. $P$ values of 0.05 or lower were considered statistically significant.

Analyses with publically available pathway databases: Biocarta pathway (San Diego, CA) and GeneAssist (Applied Biosystems, Waltham, MA) are publically available pathway databases. In addition to KEGG, supplementary analyses of gene sets were performed with each of these databases. For pathway selection, three upregulated genes (granzyme A: Gzma; cytochrome P450, family 26 , subfamily b, polypeptide 1: Cyp26b1; and activating transcription factor 3: Atf3) and three downregulated genes (solute carrier family 41 , member 3: Slc41a3; solute carrier family 46, member 2: Slc46a2; and nuclear receptor subfamily 1 , group $\mathrm{D}$, member 1 : Nr1d1) were used.

Analysis with Biocarta pathway: Biocarta pathway (San Diego, $\mathrm{CA}$ ) is an open-source database; the information is displayed in a graphical format, and known genomic and proteomic relationships are mapped. In connection with the six selected genes, a granzyme A-mediated apoptosis pathway was retrieved for Gzma. Using previously published methods, a gene-set analysis was performed with this pathway [18].

Analysis with GeneAssist: More than 350 different pathways are currently available in GeneAssist (Applied Biosystems, Waltham, MA). Illustrations show molecular interactions and cellular compartments. In connection with the six selected genes, the following five pathways were found in this database: the granzyme, granzyme A, IL 9 pathways (for Gzma), and the MAPK signaling 
Citation: Takamiya M, Saigusa K, Dewa K. DNA Microarray Analysis of Hypothermic Murine Myocardium to Study Pathophysiology and Identify Forensic Biomarkers. J Forensic Investigation. 2016; 4(1): 11.

ISSN: $2330-0396$

Table 1: Genes upregulated by hypothermia in myocardium arranged in descending order based on fold-change.

\begin{tabular}{|c|c|c|c|c|}
\hline Probe name & Fold change & Description & Symbol & RefSeq \\
\hline A_55_P1960148 & 3.310967386 & & & \\
\hline A_55_P2094060 & 3.258506336 & granzyme A & Gzma & NM_010370 \\
\hline A_51_P509679 & 3.207406257 & & & \\
\hline A_51_P501844 & 2.523991759 & $\begin{array}{l}\text { cytochrome } \mathrm{P} 450 \text {, family } 26 \text {, subfamily b, } \\
\text { polypeptide } 1\end{array}$ & Cyp26b1 & NM_001177713, NM_175475 \\
\hline A_55_P2220937 & 2.213662067 & OTU domain containing 1 & Otud1 & NM_027715 \\
\hline A_51_P153486 & 2.062825093 & DnaJ (Hsp40) homolog, subfamily B, member 1 & Dnajb1 & NM_018808 \\
\hline A_55_P2024155 & 2.02340035 & zinc finger and BTB domain containing 16 & Zbtb16 & NM_001033324 \\
\hline A_55_P2185330 & 1.994610652 & predicted gene 10914 & Gm10914 & XR_141300, XR_141788 \\
\hline A_55_P2087984 & 1.978908627 & $\begin{array}{l}\text { DnaJ (Hsp40) homolog, subfamily A, member } \\
1\end{array}$ & Dnaja1 & $\begin{array}{c}\text { NM_001164671, } \\
\text { NM_001164672, NM_008298 }\end{array}$ \\
\hline A_55_P1993404 & 1.95759763 & & & \\
\hline A_55_P2098120 & 1.951765504 & EMI domain containing 2 & Emid2 & NM_024474 \\
\hline A_51_P511250 & 1.929251998 & family with sequence similarity 46 , member $B$ & Fam46b & NM_175307 \\
\hline A_55_P1990314 & 1.917089432 & $\begin{array}{l}\text { ELAV (embryonic lethal, abnormal vision, } \\
\text { Drosophila)-like } 4 \text { (Hu antigen D) }\end{array}$ & Elavl4 & $\begin{array}{c}\text { NM_001038698, } \\
\text { NM_001163397, } \\
\text { NM_001163399, NM_010488 }\end{array}$ \\
\hline A_55_P2165869 & 1.904172132 & $\begin{array}{l}\text { CCAAT/enhancer binding protein (C/EBP), } \\
\text { beta }\end{array}$ & Cebpb & NM_009883 \\
\hline A_51_P113178 & 1.88886637 & RIKEN cDNA 6530418L21 gene & 6530418-L21Rik & NM_001163356, NM_175398 \\
\hline A_55_P2040026 & 1.881154835 & integrin alpha 4 & $\operatorname{ltga} 4$ & NM_010576 \\
\hline A_55_P2073612 & 1.849744873 & fibroblast growth factor 6 & Fgf6 & NM_010204 \\
\hline A_55_P2064741 & 1.832918197 & neuromedin B & $\mathrm{Nmb}$ & NM_026523 \\
\hline A_55_P1954271 & 1.80959085 & EMI domain containing 2 & Emid2 & NM_024474 \\
\hline A_55_P2033665 & 1.791293364 & & & \\
\hline A_55_P2135967 & 1.786622703 & & & \\
\hline A_55_P1980521 & 1.776449775 & coiled-coil domain containing $85 \mathrm{~A}$ & Ccdc85a & $\begin{array}{c}\text { NM_181577, NM_001166661, } \\
\text { NM_001166662 }\end{array}$ \\
\hline A_55_P2014506 & 1.764043577 & S-adenosylmethionine decarboxylase 2 & Amd2 & NM_007444 \\
\hline A_55_P2095118 & 1.761115416 & RIKEN cDNA $2700023 E 23$ gene & 2700023-E23Rik & NR_015531 \\
\hline A_51_P406557 & 1.743799778 & expressed sequence Al464131 & Al464131 & NM_001085515 \\
\hline A_55_P2173073 & 1.72924322 & zinc finger protein 931 & Zfp931 & NM_001162922 \\
\hline A_66_P102090 & 1.700395481 & $\begin{array}{l}\text { protein kinase, membrane associated } \\
\text { tyrosine/threonine } 1\end{array}$ & Pkmyt1 & NM_023058 \\
\hline A_52_P38639 & 1.691520545 & fermitin family homolog 3 (Drosophila) & Fermt3 & NM_153795 \\
\hline A_55_P2126269 & 1.690532158 & neuromedin B & $\mathrm{Nmb}$ & NM_026523 \\
\hline A_55_P2000521 & 1.68909796 & $\begin{array}{l}\text { LON peptidase } \mathrm{N} \text {-terminal domain and ring } \\
\text { finger } 1\end{array}$ & Lonrf1 & NM_001081150 \\
\hline A_55_P2279807 & 1.689042278 & RIKEN cDNA 6720427107 gene & 6720427-I07Rik & \\
\hline A_55_P2172274 & 1.679279997 & structural maintenance of chromosomes 2 & Smc2 & NM_008017 \\
\hline A_55_P1997225 & 1.64774735 & $\begin{array}{l}\text { ArfGAP with GTPase domain, ankyrin repeat } \\
\text { and PH domain } 2\end{array}$ & Agap2 & NM_001033263 \\
\hline A_55_P2344608 & 1.638536374 & $\begin{array}{l}\text { DNA segment, Chr } 7 \text {, Wayne State University } \\
130 \text {, expressed }\end{array}$ & D7Wsu130e & \\
\hline A_55_P1967133 & 1.638386235 & $\begin{array}{l}\text { protein phosphatase 1, regulatory (inhibitor) } \\
\text { subunit } 3 B\end{array}$ & Ppp1r3b & NM_177741 \\
\hline
\end{tabular}


Citation: Takamiya M, Saigusa K, Dewa K. DNA Microarray Analysis of Hypothermic Murine Myocardium to Study Pathophysiology and Identify Forensic Biomarkers. J Forensic Investigation. 2016; 4(1): 11.

ISSN: 2330-0396

\begin{tabular}{|c|c|c|c|c|}
\hline A_55_P1974347 & 1.634805044 & family with sequence similarity 126 , member B & Fam126b & NM_172513 \\
\hline A_55_P2161675 & 1.632035965 & zinc finger protein 133, pseudogene & Zfp133-ps & NR_033459 \\
\hline A_55_P2014511 & 1.623175349 & S-adenosylmethionine decarboxylase 2 & Amd2 & NM_007444 \\
\hline A_55_P2087985 & 1.621794809 & & & \\
\hline A_55_P1991778 & 1.620374684 & RIKEN cDNA $2310028 \mathrm{H} 24$ gene & 2310028-H24Rik & NM_001159583, NM_027993 \\
\hline A_55_P1997300 & 1.619203036 & family with sequence similarity 54 , member $\mathrm{A}$ & Fam54a & NM_027930 \\
\hline A_55_P2011727 & 1.613928091 & neuralized homolog 1b (Drosophila) & Neurl1b & NM_001081656 \\
\hline A_55_P2031436 & 1.613402504 & lymphocyte antigen 6 complex, locus $E$ & Ly6e & $\begin{array}{c}\text { NM_001164039, } \\
\text { NM_001164040, } \\
\text { NM_008529, NM_001164036, } \\
\text { NM_001164037, } \\
\text { NM_001164038 }\end{array}$ \\
\hline A_55_P2034864 & 1.608376375 & tubulin, beta $2 \mathrm{~B}$ class IIB & Tubb2b & NM_023716 \\
\hline A_51_P212741 & 1.603121499 & sodium channel, voltage-gated, type II, beta & Scn2b & NM_001014761 \\
\hline A_55_P2045682 & 1.60071475 & $\begin{array}{l}\text { Ras association (RalGDS/AF-6) domain } \\
\text { family member } 5\end{array}$ & Rassf5 & NM_018750 \\
\hline
\end{tabular}

Table 2: Genes downregulated by hypothermia in myocardium arranged in ascending order based on fold-change.

\begin{tabular}{|c|c|c|c|c|}
\hline Probe name & Fold change & Description & Symbol & RefSeq \\
\hline A_55_P2041286 & 0.377100195 & predicted gene 3970 & Gm3970 & XM_001479374, XM_001479641 \\
\hline A_51_P442097 & 0.462881497 & solute carrier family 41 , member 3 & Slc41a3 & NM_001037493, NM_027868 \\
\hline A_55_P2219731 & 0.464501513 & expressed sequence Al413759 & Al413759 & \\
\hline A_55_P2021187 & 0.478583545 & $\begin{array}{l}\text { metastasis associated lung adenocarcinoma } \\
\text { transcript } 1 \text { (non-coding RNA) }\end{array}$ & Malat1 & NR_002847 \\
\hline A_51_P185763 & 0.478656498 & solute carrier family 46 , member 2 & Slc46a2 & NM_021053 \\
\hline A_55_P1975425 & 0.487999069 & RIKEN cDNA 2210417A02 gene & 2210417-A02Rik & NR_028285 \\
\hline A_51_P223776 & 0.493093691 & $\begin{array}{l}\text { nuclear receptor subfamily } 1 \text {, group } D \text {, member } \\
1\end{array}$ & $\mathrm{Nr} 1 \mathrm{~d} 1$ & NM_145434 \\
\hline A_55_P1991693 & 0.49658256 & $\begin{array}{l}\text { peroxisome proliferative activated receptor, } \\
\text { gamma, coactivator-related } 1\end{array}$ & Pprc1 & NM_001081214, NM_145504 \\
\hline A_55_P1986711 & 0.502051616 & & & \\
\hline A_55_P2185185 & 0.515100662 & transmembrane protein 28 & Tmem28 & NM_001081283 \\
\hline A_52_P337232 & 0.528463487 & RIKEN cDNA B230340J04 gene & B230340-J04Rik & NM_177234 \\
\hline A_55_P2053923 & 0.534205006 & RAB17, member RAS oncogene family & Rab17 & NM_008998, NM_001159725 \\
\hline A_55_P1985638 & 0.535924115 & shisa homolog 7 (Xenopuslaevis) & Shisa7 & NM_172737 \\
\hline A_55_P2201020 & 0.541205985 & expressed sequence Al790442 & Al790442 & \\
\hline A_66_P120770 & 0.5438703 & $\begin{array}{l}\text { tyrosine 3-monooxygenase/tryptophan } \\
\text { 5-monooxygenase activation protein, zeta } \\
\text { polypeptide }\end{array}$ & Ywhaz & $\begin{array}{c}\text { NM_001253805, } \\
\text { NM_001253806, } \\
\text { NM_001253807, NM_011740 }\end{array}$ \\
\hline A_55_P2018836 & 0.546349483 & & & \\
\hline A_55_P2049687 & 0.546643661 & ephrin A2 & Efna2 & NM_007909 \\
\hline A_55_P2063937 & 0.548479194 & & & \\
\hline A_55_P2180744 & 0.551811504 & calsyntenin 3 & Clstn3 & NM_153508 \\
\hline A_55_P2107247 & 0.561537303 & testis-specific serine kinase 5 & Tssk5 & NM_183099 \\
\hline A_55_P2136533 & 0.561899659 & myeloid/lymphoid or mixed-lineage leukemia 2 & MII2 & $\begin{array}{l}\text { NM_001033388, } \\
\text { NM_001033276 }\end{array}$ \\
\hline A_51_P436491 & 0.565783198 & leucine rich repeat and Ig domain containing 3 & Lingo3 & NM_001013758 \\
\hline A_55_P2036813 & 0.570474221 & histone cluster $3, \mathrm{H} 2 \mathrm{ba}$ & Hist3h2ba & NM_030082 \\
\hline A_55_P2121613 & 0.576058902 & SRY-box containing gene 4 & Sox4 & NM_009238 \\
\hline A_51_P240253 & 0.585840952 & Ras-related associated with diabetes & Rrad & NM_019662 \\
\hline A_51_P415395 & 0.586204359 & $\mathrm{C} 2$ calcium-dependent domain containing $4 \mathrm{~B}$ & $\mathrm{C} 2 \mathrm{~cd} 4 \mathrm{~b}$ & NM_001081314 \\
\hline A_55_P2025483 & 0.588201839 & Rieske (Fe-S) domain containing & Rfesd & $\begin{array}{c}\text { NM_001131068, } \\
\text { NM_001131069, NM_178916 }\end{array}$ \\
\hline
\end{tabular}


Citation: Takamiya M, Saigusa K, Dewa K. DNA Microarray Analysis of Hypothermic Murine Myocardium to Study Pathophysiology and Identify Forensic Biomarkers. J Forensic Investigation. 2016; 4(1): 11.

ISSN: 2330-0396

\begin{tabular}{|l|l|l|l|}
\hline A_55_P2119927 & 0.589530762 & & \\
\hline A_55_P2010539 & 0.589885397 & & \\
\hline A_55_P2007776 & 0.598626935 & cation channel, sperm associated 2 & Catsper2 \\
\hline
\end{tabular}

and TNF signaling pathways (for Atf 3 ). Using previously published methods, gene-set analyses were performed with these pathways [18].

Gene functional-category analysis: Gene functional-category analyses were performed. The number of genes corresponding to each Gene Ontology term among all genes was compared to the number among differentially regulated genes using Fisher's Exact Test. P values of 0.05 or lower was considered statistically significant.

\section{Quantitative PCR}

To validate selected aspects of microarray results, three upregulated genes (Gzma, Cyp26b1, Atf3; Table 1) and three downregulated genes (Slc41a3, Slc46a2, Nr1d1; Table 2) were selected for measurement by quantitative PCR.

RNA extraction and reverse transcription: Total RNA was extracted from tissues using an RNeasy Fibrous Tissue Mini Kit (Qiagen, Valencia, CA). An absorptiometer and electrophoresis through a $1 \%$ agarose gel were used to confirm the quality of the RNA samples; the quality control criteria were as follows: OD260/280 > 1.5, OD260/230 > 1.0, no degradation in electrophoresis with 28S and $18 \mathrm{~S}$ ribosomal RNA bands. The RNA was treated with TURBO DNase (Applied Biosystems, Waltham, MA). A High-Capacity cDNA Reverse Transcription kit with RNase inhibitor (Applied Biosystems, Waltham, MA) was then used according to the manufacturer's instructions to synthesize cDNA.

Real-time quantitative PCR: TaqMan Gene Expression Assays (Applied Biosystems, Waltham, MA) are the most reliable sets of pre- designed quantitative real-time PCR assays. TaqMan Gene Expression Assays (Applied Biosystems, Waltham, MA) have been designed using the validated bioinformatics pipeline and run with the same PCR protocol; this protocol eliminates the need for time-consuming primer design or PCR optimization. TaqMan Gene Expression Assays (Applied Biosystems, Waltham, MA) are used as the gold standard technology in mRNA quantification. In the present study, TaqMan Gene Expression Assays (Applied Biosystems, Waltham, MA) were used with the following primers and probes:

Gzma: Mm01304452_m1, NM_010370.2,59bp

Cyp26b1: Mm00558507_m1, NM_001177713.1, NM_175475.3, $75 \mathrm{bp}$

Atf3: Mm00476032_m1, NM_007498.3,61bp

Slc41a3: Mm01182529_m1, NM_001037493.2, NM_027868.2, $91 \mathrm{bp}$

Slc46a2: Mm00498614_m1, NM_021053.4,64bp

Nr1d1: Mm00520708_m1, NM_145434.4,62bp

A value that represents the stability of individual internalstandard genes was used to select the internal-standard gene; values for $\beta$-actin, glyceraldehyde-3-phosphate dehydrogenase (GAPDH), and $18 \mathrm{~S}$ ribosomal RNA were $1.68,1.52$ and 1.96 respectively [19]. Therefore, GAPDH was used as the internal-standard gene. GAPDH primers and probes are supplied with TaqMan Gene Expression Assays (Mm99999915_g1, NM_001289726.1, NM_008084.3, 107bp,

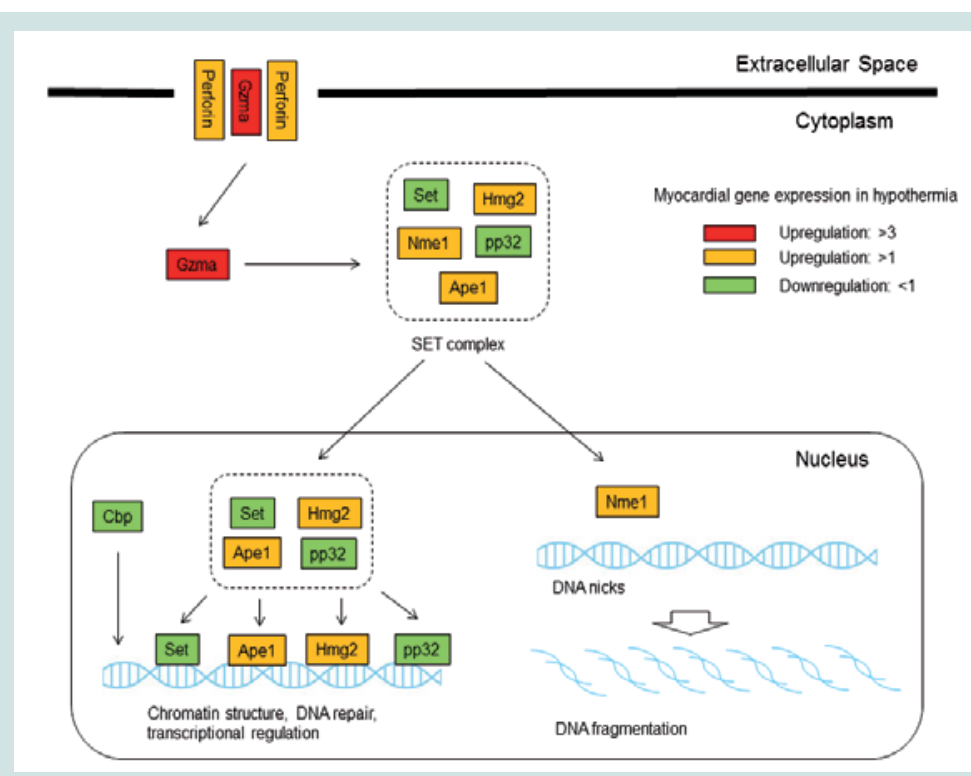

Figure 1: Hypothermia-induced granzyme A-mediated apoptosis pathway. Granzyme A causes DNA fragmentation. The pathway shown was constructed based on information from the Biocarta pathway database (San Diego, CA). Gene names are as follows: Ape1: apurinic/apyrimidinic endonuclease 1; Cbp: CREB binding protein; Gzma: granzyme A; Hmg2: high-mobility group protein B2; Nme1: NME/NM23 nucleoside diphosphate kinase 1; pp32: acidic (leucine-rich) nuclear phosphoprotein 32 family, member A; Set: SET nuclear oncogene. 

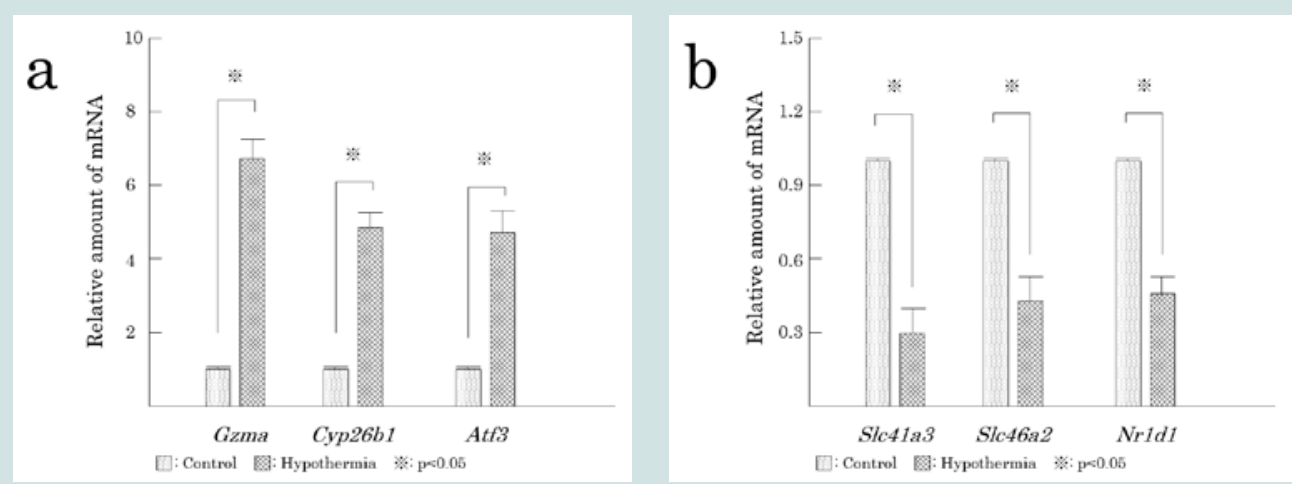

Figure 2: Real-time quantitative PCR analysis of six representative genes, three upregulated (a) and three downregulated (b). Hypothermia-associated mRNA levels relative to control levels. Values are each a mean $\pm S D(n=10$ for hypothermic mice, $n=10$ for control mice).
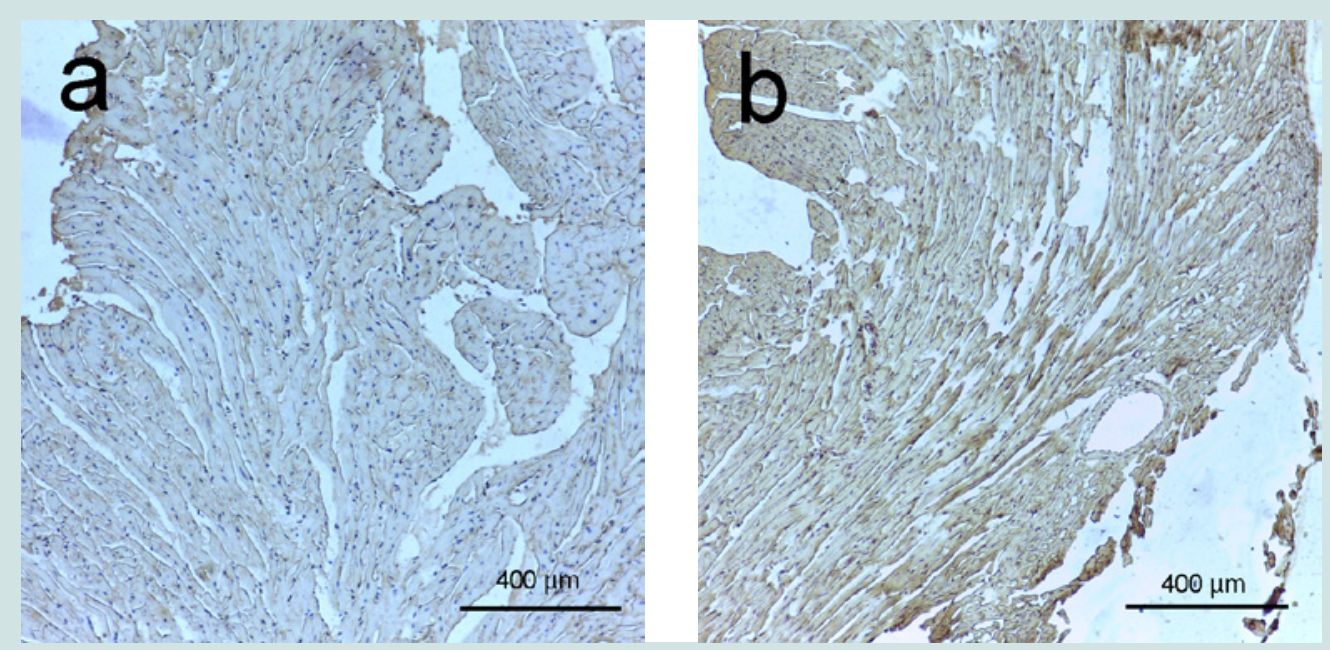

Figure 3: Immunohistochemistry of Granzyme A. Granzyme A signal was not evident in control specimens from left ventricle tissue (a). Cardiac myocytes showed some cytoplasmic expression of granzyme A in specimens from each hypothermic left ventricle (b). Granzyme A expression was not evident in any endocardial, epicardial, or endothelial cells.

Applied Biosystems, Waltham, MA). Real-time quantitative PCR was performed using a PRISM 7500 sequence detector (Applied Biosystems, Waltham, MA). Individual 50- $\mu$ l reaction mixtures containing TaqMan Gene Expression Master Mix (Applied Biosystems, Waltham, MA) and the thermal cycler conditions recommended in the manufacturer's instructions were used. All samples were analyzed in triplicate. No amplification was evident in any no-template control. The relative expression of each target gene was calculated via the $\Delta \Delta \mathrm{Ct}$ method as described in the manufacturer's instructions (Applied Biosystems, Waltham, MA). Differences in gene expression between control and hypothermic myocardium were assessed via the Student's t test; P values of 0.05 or lower were considered statistically significant. In addition, this experiment was checked according to the quantitative real-time PCR experiment (MIQE) guidelines (Supplement 2) [20].

\section{Immunohistochemistry}

Specimens were fixed in $4 \%$ buffered formalin, embedded in paraffin, and sectioned at a thickness of $2.5 \mu \mathrm{m}$. Each section was stained with hematoxylin and eosin (H\&E). In order to analyze histological dynamics, immunohistochemistry was performed. No commercially suitable antibodies were found for two upregulated genes (Cyp26b1, Atf3) or three downregulated genes (Slc41a3, Slc46a2, Nr1d1). Therefore, expression of granzyme A was examined using rabbit anti-granzyme A (Cloud-Clone, Houston, TX) as the primary antibodies. Antigen activation was performed with a microwave oven and antigen activating solution (Nichirei, Tokyo, Japan). Sections were incubated with primary antibodies diluted 1:25 for $12 \mathrm{~h}$ in a humid chamber at $4{ }^{\circ} \mathrm{C}$. Thereafter, sections were incubated with peroxidase-conjugated secondary antibody according to the manufacturer's instructions (Histofine MAX-PO (R), Nichirei, Tokyo, Japan). The chromogen used to visualize antibody signal was 3, 3-diamino-benzidine (Nichirei, Tokyo, Japan), and the specimens were counterstained with hematoxylin. Quantitative analysis was difficult in cardiac tissue; therefore, expression was assessed qualitatively via light microscope.

\section{Results \\ DNA microarrays}

Quality control: With the quality control measures, data from 17870 of the 39485 microarray genes could be used for further analysis. 
Citation: Takamiya M, Saigusa K, Dewa K. DNA Microarray Analysis of Hypothermic Murine Myocardium to Study Pathophysiology and Identify Forensic Biomarkers. J Forensic Investigation. 2016; 4(1): 11.

Identification of significantly regulated genes: We identified 3438 genes that exhibited hypothermia-induced differential expression in mouse myocardium; 1704 were upregulated, and 1734 were downregulated. Of the upregulated genes, 120 genes increased by $>1.5$-fold and $\leq 2$-fold, five by $>2$-fold and $\leq 3$-fold, and three by $>3$-fold. Among the genes confirmed as upregulated, granzyme A was the most upregulated gene with a 3.26-fold increase. For the downregulated genes, expression in hypothermic myocardium was lower than in control myocardium by $<0.6$-fold and $\geq 0.5$-fold for 22 genes, by $<0.5$-fold and $\geq 0.4$-fold for seven genes, and by $<0.4$ fold for one gene. Solute carrier family 41 member 3 was the most downregulated gene with a 0.463 -fold reduction. Upregulated genes and downregulated genes were arranged in order (descending or ascending, respectively) with respect to fold-change; Table 1 lists the 50 upregulated genes with a change greater than 1.6-fold, and Table 2 lists the 30 downregulated genes with a change of 0.6 -fold or lower.

\section{Gene-set analysis:}

KEGG analysis: Significant variations were found in 79 pathways, and the gene sets that were upregulated or downregulated are summarized in Tables 3 and 4 respectively. A total of 57 pathways were significantly upregulated, and 22 pathways were downregulated. Upregulation of the viral myocarditis pathway was evident. But, no pathway related to granzyme A and/or activating transcription factor 3 was identified as significantly altered in hypothermic myocardium.

\section{Publically available database analysis:}

Analysis with Biocarta pathway: In connection with the six selected genes (Gzma, Cyp26b1, Atf3, Slc41a3, Slc46a2 and Nr1d1), a granzyme A-mediated apoptosis pathway was retrieved for Gzma. This pathway was significantly upregulated (Figure 1 and Table 5).

Analysis with GeneAssist: In connection with the six selected genes, the following five pathways were found in this database: the granzyme, granzyme A, and IL 9 pathways for Gzma and the MAPK signaling and TNF signaling pathways for Atf3. Among these five pathways, the granzyme pathway, granzyme A pathway (for Gzma), and MAPK signaling (for Atf3) were significantly upregulated (Table $5)$.

Analysis of gene function category: To investigate the biological functions involving the differentially regulated genes, we performed Gene Ontology category analysis. The 10 categories most commonly associated with these differentially regulated (upregulated or downregulated) genes included biological process, molecular function, and cellular component. The most commonly represented categories among upregulated and downregulated genes were cellular process, binding, cell, and cell part (Supplements 3 and 4).

\section{Validation of gene expression results by quantitative PCR}

We used quantitative PCR to validate microarray findings for three upregulated and three downregulated genes (Figure 2). Quantitative PCR findings were consistent with DNA microarray findings except that fold differences detected by the two methods were not identical for each gene. Among the downregulated genes, Slc41a3 was decreased to a greater extent than Slc46a2 or Nr1d1 was.

\section{Immunohistochemical analyses}

Myocardium remained stable based on H\&E-stained specimens.
No infiltration of inflammatory cells was seen in hypothermic specimens. Based on the immunohistochemical analyses, granzyme A expression was not evident in any control myocardium specimen; in contrast, slight granzyme A expression was evident in cytoplasm of hypothermic cardiac myocytes. There was no granzyme A expression in endocardial, epicardial, or endothelial cells (Figure 3).

\section{Discussion}

In the present study, DNA microarray analyses were performed with control and hypothermic ventricular myocardium. A total of 3438 genes were found to be differentially expressed in hypothermic tissue; specifically, 1704 were upregulated, and 1734 were downregulated. Cardiac candidates for forensic biomarkers of hypothermia were Gzma, Cyp26b1, and Atf3 among the upregulated genes (Table 1) and Slc41a3, Slc46a2, and Nr1d1 among the downregulated genes (Table 2). Needless to say, the possibility exists that other currently unidentified factors that are differentially expressed may be useful for diagnosing hypothermia. To our knowledge, no previous studies of hypothermia have identified a connection between hypothermia and Gzma, Cyp26b1, Atf3, Slc41a3, Slc46a2 or Nr1d1 expression. The Gene Ontology analysis indicated that cellular process, binding, cell, and cell part were significantly highly represented categories. The gene-set analysis revealed that cell death pathways related to granzyme A were upregulated and that these pathways may be involved in the cardiac pathogenesis of hypothermia.

Multiple types of cell death have been described; these include apoptosis, autophagy, necrosis, senescence, and mitotic catastrophe [21]. Some genes identified here as differentially regulated in response to hypothermia are modulators of one or more cell-death pathways; for example, granzyme A was upregulated in this study, and this protein leads to cell death by mediating cleavage of DNA molecules in the nucleus and of molecules in the nuclear envelope or mitochondrial membranes [21,22]. In addition, granzyme A plays an important role in inflammation [21]. Extracellular matrix components such as vitronectin, fibronectin, fibrinogen, laminin, and proteoglycans can be cleaved by granzyme A and this degradation may facilitate movements of leukocytes [21,23]. Granzyme A can also induce secretion of cytokines [24-26]. Activating transcription factor 3 was also upregulated in the hypothermic myocardium, and it is known to affect genes involved in apoptosis [27].

Decreased cardiac output and fatal arrhythmias are observed during hypothermia [14,15]. Histological analyses reveal that hypothermia causes degenerative foci in myocardium [28]; these foci consist of myofibrosis, calcifications, hyperchromasia, contraction bands, waving, discoloration and fragmentation of the fibers, edema, hemorrhages [3,29], coagulation necrosis, extravasation of red cells [3], inflammatory reactions (including cellular infiltration), granulation, and scarring [28,30,31]. Fatty changes in myocardium are also observed [32]. These histological lesions could act as foci of ventricular fibrillation [31]. Putative causative mechanisms include myocardial ischemia [33] mediated by platelet thrombi [31], increased blood viscosity [29,34-36], insufficient coronary perfusion, and catecholamine mobilizations [29]. Interestingly, our current findings suggested a previously unidentified putative mechanism for these lesions; specifically, hypothermia may induce myocardial cell death via granzyme A and activating transcription factor 3 , and 
Citation: Takamiya M, Saigusa K, Dewa K. DNA Microarray Analysis of Hypothermic Murine Myocardium to Study Pathophysiology and Identify Forensic Biomarkers. J Forensic Investigation. 2016; 4(1): 11.

ISSN: 2330-0396

Table 3: Gene-set analysis of the myocardial transcriptome in response to hypothermia with gene sets arranged by decreasing Z-score.

\begin{tabular}{|c|c|c|c|c|c|}
\hline KEGG map & Map name & $\begin{array}{c}\text { Number of } \\
\text { genes }\end{array}$ & p-value & $\begin{array}{l}\text { Fold change } \\
\text { average }\end{array}$ & Z score \\
\hline mmu05330 & Allograft rejection & 29 & $0.00 \mathrm{E}+00$ & 0.352 & 8.544 \\
\hline mmu05332 & Graft-versus-host disease & 30 & $8.88 \mathrm{E}-16$ & 0.327 & 8.056 \\
\hline mmu04514 & Cell adhesion molecules (CAMs) & 94 & $9.10 \mathrm{E}-15$ & 0.181 & 7.750 \\
\hline mmu04940 & Type I diabetes mellitus & 37 & 8.04E-14 & 0.274 & 7.470 \\
\hline mmu04650 & Natural killer cell mediated cytotoxicity & 112 & $5.60 \mathrm{E}-12$ & 0.149 & 6.889 \\
\hline mmu05150 & Staphylococcus aureus infection & 29 & $1.55 \mathrm{E}-09$ & 0.251 & 6.039 \\
\hline mmu04145 & Phagosome & 155 & 2.95E-09 & 0.111 & 5.935 \\
\hline mmu05322 & Systemic lupus erythematosus & 90 & 6.44E-09 & 0.141 & 5.805 \\
\hline mmu05416 & Viral myocarditis & 85 & 2.63E-08 & 0.139 & 5.564 \\
\hline mmu05164 & Influenza A & 160 & $8.74 \mathrm{E}-08$ & 0.100 & 5.351 \\
\hline mmu05168 & Herpes simplex infection & 183 & 1.17E-07 & 0.093 & 5.299 \\
\hline mmu05166 & HTLV-I infection & 273 & $1.30 \mathrm{E}-07$ & 0.077 & 5.279 \\
\hline mmu05340 & Primary immunodeficiency & 25 & $2.54 \mathrm{E}-06$ & 0.212 & 4.705 \\
\hline mmu05203 & Viral carcinogenesis & 218 & $6.44 \mathrm{E}-06$ & 0.074 & 4.511 \\
\hline mmu04662 & B cell receptor signaling pathway & 92 & $7.80 \mathrm{E}-06$ & 0.109 & 4.471 \\
\hline mmu04060 & Cytokine-cytokine receptor interaction & 145 & $1.08 \mathrm{E}-05$ & 0.087 & 4.400 \\
\hline mmu04062 & Chemokine signaling pathway & 168 & $1.51 \mathrm{E}-05$ & 0.080 & 4.327 \\
\hline mmu04380 & Osteoclast differentiation & 129 & $3.68 \mathrm{E}-05$ & 0.087 & 4.126 \\
\hline mmu04810 & Regulation of actin cytoskeleton & 229 & $6.53 \mathrm{E}-05$ & 0.065 & 3.993 \\
\hline mmu05202 & Transcriptional misregulation in cancer & 160 & $2.94 \mathrm{E}-04$ & 0.070 & 3.620 \\
\hline mmu05310 & Asthma & 8 & 3.07E-04 & 0.285 & 3.609 \\
\hline mmu04510 & Focal adhesion & 218 & $5.52 \mathrm{E}-04$ & 0.059 & 3.454 \\
\hline mmu05140 & Leishmania infection & 63 & 7.12E-04 & 0.100 & 3.385 \\
\hline mmu04110 & Cell cycle & 123 & $9.65 \mathrm{E}-04$ & 0.072 & 3.301 \\
\hline mmu05152 & Tuberculosis & 154 & $1.01 \mathrm{E}-03$ & 0.065 & 3.286 \\
\hline mmu05034 & Alcoholism & 148 & $1.03 E-03$ & 0.066 & 3.283 \\
\hline mmu04640 & Hematopoietic cell lineage & 54 & $1.21 \mathrm{E}-03$ & 0.103 & 3.236 \\
\hline mmu05200 & Pathways in cancer & 331 & $1.62 \mathrm{E}-03$ & 0.045 & 3.152 \\
\hline mmu03030 & DNA Replication & 39 & $2.45 \mathrm{E}-03$ & 0.113 & 3.030 \\
\hline mmu04666 & Fc gamma R-mediated phagocytosis & 112 & $2.68 \mathrm{E}-03$ & 0.069 & 3.003 \\
\hline mmu05143 & African trypanosomiasis & 23 & $2.90 \mathrm{E}-03$ & 0.143 & 2.978 \\
\hline mmu05222 & Small cell lung cancer & 90 & 4.90E-03 & 0.072 & 2.814 \\
\hline mmu05133 & Pertussis & 72 & 7.17E-03 & 0.077 & 2.689 \\
\hline mmu04540 & Gap junction & 88 & 7.90E-03 & 0.069 & 2.657 \\
\hline mmu04630 & Jak-STAT signaling pathway & 110 & $8.14 \mathrm{E}-03$ & 0.063 & 2.646 \\
\hline mmu05169 & Epstein-Barr virus infection & 232 & $8.97 \mathrm{E}-03$ & 0.045 & 2.613 \\
\hline mmu04512 & ECM-receptor interaction & 67 & $9.22 \mathrm{E}-03$ & 0.077 & 2.604 \\
\hline mmu04623 & Cytosolic DNA-sensing pathway & 49 & $9.62 \mathrm{E}-03$ & 0.088 & 2.589 \\
\hline mmu05323 & Rheumatoid arthritis & 59 & $2.32 \mathrm{E}-02$ & 0.072 & 2.270 \\
\hline
\end{tabular}


Citation: Takamiya M, Saigusa K, Dewa K. DNA Microarray Analysis of Hypothermic Murine Myocardium to Study Pathophysiology and Identify Forensic Biomarkers. J Forensic Investigation. 2016; 4(1): 11.

ISSN: 2330-0396

\begin{tabular}{|c|c|c|c|c|c|}
\hline mmu05160 & Hepatitis C & 123 & 2.40E-02 & 0.052 & 2.258 \\
\hline mmu05033 & Nicotine addiction & 6 & $2.72 \mathrm{E}-02$ & 0.204 & 2.209 \\
\hline mmu04210 & Apoptosis & 87 & 2.78E-02 & 0.059 & 2.200 \\
\hline mmu05144 & Malaria & 34 & 2.97E-02 & 0.089 & 2.174 \\
\hline mmu05215 & Prostate cancer & 105 & 3.36E-02 & 0.053 & 2.124 \\
\hline mmu05145 & Toxoplasmosis & 123 & $3.40 \mathrm{E}-02$ & 0.049 & 2.120 \\
\hline mmu04973 & Carbohydrate digestion and absorption & 31 & $3.50 \mathrm{E}-02$ & 0.090 & 2.108 \\
\hline mmu04620 & Toll-like receptor signaling pathway & 87 & 3.62E-02 & 0.056 & 2.095 \\
\hline mmu05032 & Morphine addiction & 71 & 3.66E-02 & 0.062 & 2.091 \\
\hline mmu05218 & Melanoma & 78 & 3.91E-02 & 0.058 & 2.063 \\
\hline mmu04740 & Olfactory transduction & 47 & 4.10E-02 & 0.072 & 2.043 \\
\hline mmu00524 & Butirosin and neomycin biosynthesis & 5 & 4.29E-02 & 0.204 & 2.025 \\
\hline mmu05162 & Measles & 124 & 4.54E-02 & 0.047 & 2.001 \\
\hline
\end{tabular}

Table 4: Gene-set analysis of the myocardial transcriptome in response to hypothermia with gene sets arranged by increasing Z-score.

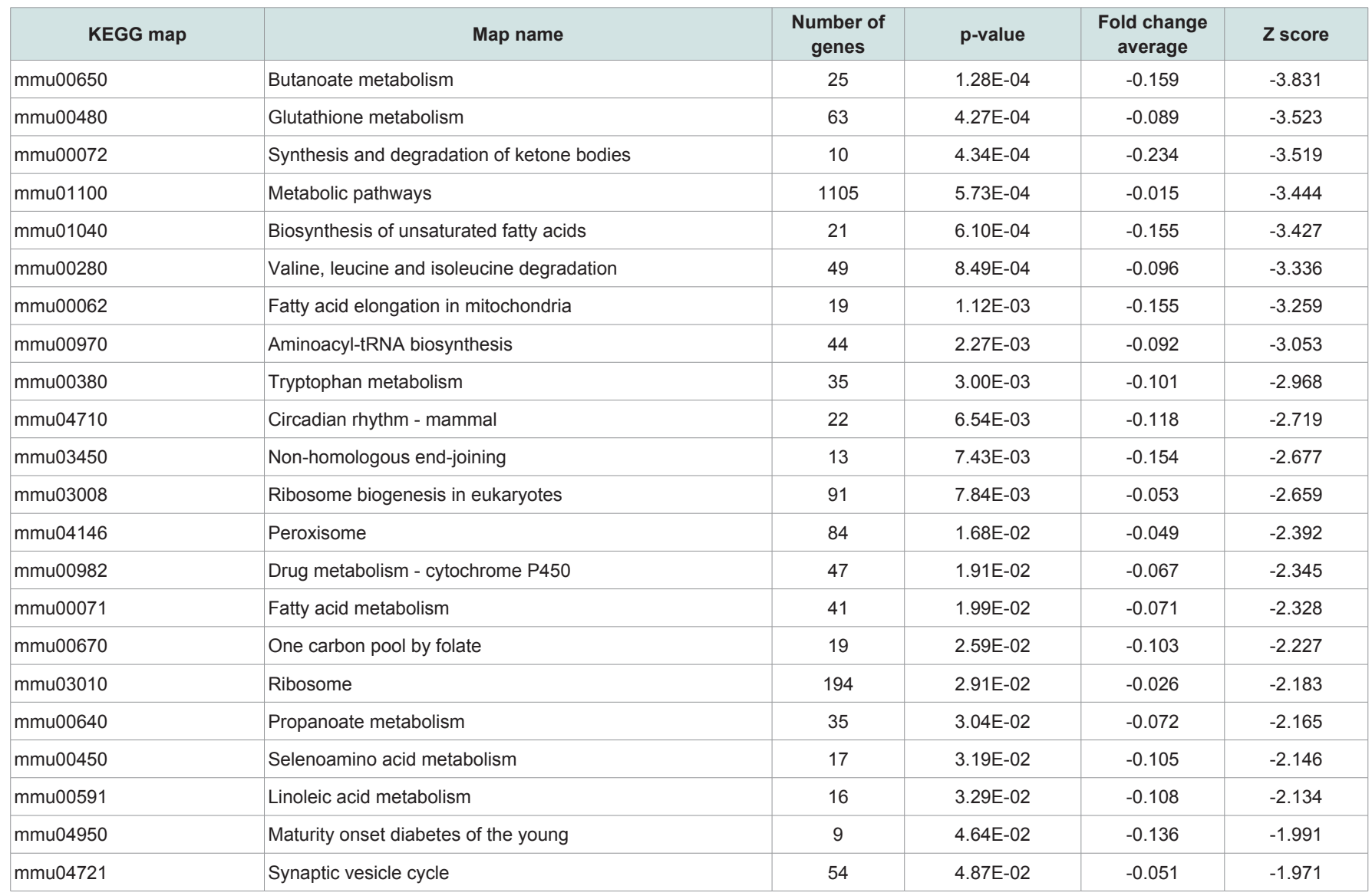

this cell death may cause some of the histological lesions and clinical symptoms characteristic of hypothermic myocardium. Some clinical studies show that hypothermia causes high mortality [13]. Myocardial cell deaths induced by hypothermia would be irreversible changes, and we postulate that this cell death may be related to the circulatory failure, resistance to treatment, and high mortality associated with hypothermia.
A compact arrangement of myocardial fibers (called interstitial narrowness) between myocardial fibers has recently been identified as a histological finding indicative of hypothermia [37]. Some pathologists have proposed that this finding is caused by dehydration during hypothermia [38]. The present transcriptome analysis did not provide substantial insight into this mechanism and related genetic pathways responsible for this phenomenon. One might say 
Citation: Takamiya M, Saigusa K, Dewa K. DNA Microarray Analysis of Hypothermic Murine Myocardium to Study Pathophysiology and Identify Forensic Biomarkers. J Forensic Investigation. 2016; 4(1): 11.

ISSN: 2330-0396

Table 5: Gene-set analyses of the myocardium transcriptome in response to hypothermia based on publically available pathway databases.

\begin{tabular}{|c|c|c|c|c|}
\hline Map name & Number of genes & p-value & $\begin{array}{l}\text { Fold change } \\
\text { average }\end{array}$ & Z score \\
\hline \multicolumn{5}{|l|}{ A. Biocarta pathway } \\
\hline Granzyme A mediated apoptosis pathway & 16 & $1.43 \mathrm{E}-02$ & 0.141 & 2.449 \\
\hline \multicolumn{5}{|l|}{ B. Geneassist } \\
\hline Granzyme A pathway & 15 & $1.53 E-02$ & 0.144 & 2.426 \\
\hline Granzyme pathway & 40 & $2.48 \mathrm{E}-02$ & 0.085 & 2.245 \\
\hline IL-9pathway & 37 & 0.707148067 & -0.006 & -0.376 \\
\hline \multicolumn{5}{|l|}{ b) Activating transcription factor 3} \\
\hline MAPK Signaling & 455 & $8.71 \mathrm{E}-03$ & 0.034 & 2.623 \\
\hline
\end{tabular}

that interstitial narrowness is a passive myocardial change caused by dehydration.

The present research demonstrated changes in gene expression in hypothermic murine myocardium and identified potential cardiac candidates for forensic biomarkers of hypothermia. The present findings suggested that myocardial cell death was induced in hypothermia and that this cell death could cause cardiac dysfunctions and high mortality during hypothermia. These data may help elucidate the pathophysiology of hypothermia. But mechanisms of hypothermia may be multifactorial and manifold. In addition, reports of forensic hypothermia investigations that use molecular biological techniques have only recently begun to appear, and traditional characteristics of hypothermia remain important for forensic diagnosis [39]. Large-scale gene analyses, including DNA microarray analyses, are promising methods for detecting forensic pathological biomarkers. However, it should be noted that applications of these gene expression data would be limited in routine forensic practices. For example, the postmortem interval could negatively affect gene expression analysis. The samples in these animal experiments were collected under ideal circumstances. After considering these transcriptomic data along with postmortem changes, expression of biomarker candidates in forensic human samples should be assessed. Because RNA decomposes in the postmortem interval, utilization of protein markers should be considered as alternative to RNA biomarkers. Therefore, analysis of the proteins encoded by candidate biomarkers identified via this DNA microarray analysis is a next step in the process of identifying clinically useful biomarkers. The present histological study also demonstrated slight expression of granzyme A in cardiac myocytes. Importantly, results of the present murine DNA microarray study may provide data applicable to the development of future immunohistochemical protocols for analysis of human forensic samples. In addition, we believe that these data are informative, not only for future forensic pathological studies, but also potentially for clinical research into hypothermia.

\section{Conclusion}

We compared the hypothermic murine myocardial transcriptome to that of a room-temperature control using DNA microarray technology; we thereby identified 3438 genes that were significantly differentially expressed in response to hypothermia. Of these genes, 1704 were upregulated and 1734 were downregulated. The gene encoding granzyme A was the most upregulated gene, and that encoding solute carrier family 41 member 3 was the most downregulated. In our gene-set analysis, significant variations were found in 79 pathways, and we suggest that pathways related to granzyme A and cell death may be involved in hypothermia-induced cardiac pathogenesis. The present study documented acute myocardial responses during hypothermia and revealed cardiac candidates that may be useful as forensic biomarkers of hypothermia. Myocardial cell death induced by granzyme A may represent an irreversible change that is related to the circulatory failure, resistance to treatment, and high mortality associated with hypothermia. Furthermore, the present microarray data may facilitate development of protocols for immunohistochemical analysis of specimens from human cases and be beneficial to clinical research on hypothermia.

\section{References}

1. Ulrich AS, Rathlev NK (2004) Hypothermia and localized cold injuries. Emerg Med Clin North Am 22: 281-298.

2. Saukko P, Knight B (2004) Neglect, starvation and hypothermia: Injury caused by cold: hypothermia. In: Saukko P, Knight B, (Eds) Knight's Forensic Pathology ( $\left.3^{\text {rd }} \mathrm{Edn}\right)$, Edward Arnold (Publishers) Ltd, CRC Press, London, pp. 414-420.

3. Hirvonen J (1976) Necropsy findings in fatal hypothermia cases. Forensic Sci 8: 155-164.

4. Aghayev E, Thali MJ, Jackowski C, Sonnenschein M, Dirnhofer R, et al (2008) MRI detects hemorrhages in the muscles of the back in hypothermia. Forensic Sci Int 176: 183-186.

5. Paton BC (1983) Accidental hypothermia. Pharmacol Ther 22: 331-377.

6. DiMaio VJ, DiMaio D (2001) Hyperthermia and Hypothermia: The effects of heat and cold. In: DiMaio VJ, DiMaio D, (Eds) Forensic pathology ( $\left.2^{\text {nd }} E d n\right)$, CRC press, Boca Raton, pp. 419-434.

7. Fisher ER, Fedor EJ, Fisher B (1957) Pathologic and histochemical observations in experimental hypothermia. AMA Arch Surg 75: 817-827.

8. Mant AK (1969) Autopsy diagnosis of accidental hypothermia. J Forensic Med 16: 126-129.

9. Preuss J, Dettmeyer R, Lignitz E, Madea B (2004) Fatty degeneration in renal tubule epithelium in accidental hypothermia victims. Forensic Sci Int 141: 131-135. 
Citation: Takamiya M, Saigusa K, Dewa K. DNA Microarray Analysis of Hypothermic Murine Myocardium to Study Pathophysiology and Identify Forensic Biomarkers. J Forensic Investigation. 2016; 4(1): 11.

10. Preuss J, Lignitz E, Dettmeyer R, Madea B (2007) Pancreatic changes in cases of death due to hypothermia. Forensic Sci Int 166: 194-198.

11. Preuss J, Dettmeyer R, Poster S, Lignitz E, Madea B (2008) The expression of heat shock protein 70 in kidneys in cases of death due to hypothermia. Forensic Sci Int 176: 248-252

12. Hirvonen J, Huttunen P (1982) Increased urinary concentration of catecholamines in hypothermia deaths. J Forensic Sci 27: 264-271.

13. Vassal T, Benoit-Gonin B, Carrat F, Guidet B, Maury E, et al. (2001) Severe accidental hypothermia treated in an ICU: prognosis and outcome. Ches 120: 1998-2003.

14. Lauri T, Leskinen M, Timisjarvi J, Hirvonen L (1991) Cardiac function in hypothermia. Arctic Med Res 50 Suppl 6: 63-66.

15. Maaravi Y, Weiss AT (1990) The effect of prolonged hypothermia on cardiac function in a young patient with accidental hypothermia. Chest 98: 1019-1020.

16. Okuda C, Saito A, Miyazaki M, Kuriyama K (1986) Alteration of the turnover of dopamine and 5-hydroxytryptamine in rat brain associated with hypothermia. Pharmacol Biochem Behav 24: 79-83.

17. Brazma A, Hingamp P, Quackenbush J, Sherlock G, Spellman P, et al (2001) Minimum information about a microarray experiment (MIAME)-toward standards for microarray data. Nat Genet 29: 365-371.

18. Kim SY, Volsky DJ (2005) PAGE: Parametric analysis of gene set enrichment. BMC Bioinformatics 6: 144 .

19. Vandesompele J, De Preter K, Pattyn F, Poppe B, Van Roy N, et al. (2002) Accurate normalization of real-time quantitative RT-PCR data by geometric averaging of multiple internal control genes. Genome Biol 3 RESEARCH0034.

20. Bustin SA, Benes V, Garson JA, Hellemans J, Huggett J, et al. (2009) The MIQE guidelines: minimum information for publication of quantitative realtime PCR experiments. Clin Chem 55: 611-622.

21. Zhou $F$ (2010) Expression of multiple granzymes by cytotoxic T lymphocyte implies that they activate diverse apoptotic pathways in target cells. Int Rev Immunol 29: 38-55.

22. Susanto O, Trapani JA, Brasacchio D (2012) Controversies in granzyme biology. Tissue Antigens 80: 477-487

23. Buzza MS, Bird PI (2006) Extracellular granzymes: current perspectives. Biol Chem 387: 827-837.

24. Metkar SS, Menaa C, Pardo J, Wang B, Wallich R, et al. (2008) Human and mouse granzyme $A$ induce a proinflammatory cytokine response. Immunity 29: $720-733$.
25. Sower LE, Klimpel GR, Hanna W, Froelich CJ (1996) Extracellular activities of human granzymes. I. Granzyme A induces IL6 and IL8 production in fibroblast and epithelial cell lines. Cell Immunol 171: 159-163.

26. Yoshikawa Y, Hirayasu H, Tsuzuki S, Fushiki T (2008) Granzyme A causes detachment of alveolar epithelial A549 cells accompanied by promotion of interleukin-8 release. Biosci Biotechnol Biochem 72: 2481-2484.

27. Turchi L, Aberdam E, Mazure N, Pouyssegur J, Deckert M, et al. (2008) Hif2alpha mediates UV-induced apoptosis through a novel ATF3-dependent death pathway. Cell Death Differ 15: 1472-1480.

28. Hirvonen J, Huttunen P, Hiltunen K (1988) Creatine phosphokinase in serum and cerebrospinal fluid, and microscopic findings in brain and heart in hypothermic rabbits. Forensic Sci Int 39: 271-278.

29. Hirvonen J, Penttinen J, Huttunen P, Saukko P (1980) Changes in the myocardium and skeletal muscle in guinea pigs in cold exposure with and without ethanol. Z Rechtsmed 84: 195-207

30. Altland PD, Highman B, Sellner RG (1974) Serum enzyme and tissue changes in shaven rabbits exposed to cold. Cryobiology 11: 296-304.

31. Sarajas HS (1964) Myocardial damage induced by immersion hypothermia Am J Cardiol 13: 355-366.

32. Preuss J, Dettmeyer R, Lignitz E, Madea B (2006) Fatty degeneration of myocardial cells as a sign of death due to hypothermia versus degenerative deposition of lipofuscin. Forensic Sci Int 159: 1-5

33. Lynch HF, Adolph EF (1957) Blood flow in small blood vessels during deep hypothermia. J Appl Physiol 11: 192-196.

34. Kanter GS (1968) Hypothermic hemoconcentration. Am J Physiol 214: $856-$ 859.

35. Keen G, Gerbode F (1963) Observations on the microcirculation during profound hypothermia. J Thorac Cardiovasc Surg 45: 252-260.

36. Taylor MJ, Bailes JE, Elrifai AM, Shih SR, Teeple E, et al. (1995) A new solution for life without blood. Asanguineous low-flow perfusion of a wholebody perfusate during 3 hours of cardiac arrest and profound hypothermia. Circulation 91: 431-444.

37. Funayama M, Morita M, Shimizu K, Shiono H, Hiraiwa K, et al. (1997) Compact arrangement of myocardial fibers in cases of fatal hypothermia. Proceeding of 14th meeting of International Association of Forensic Sciences. Curr Top Forensic Sci 3: 381-383.

38. Jolly BT, Ghezzi KT (1992) Accidental hypothermia. Emerg Med Clin North Am 10: 311-327.

39. Turk EE (2010) Hypothermia. Forensic Sci Med Pathol 6: 106-115

\section{Acknowledgements}

This study was supported by JSPS KAKENHI grant number 26460884 . 